\title{
An Introduction to Porcelain Laminates
}

\section{Sunit Kumar Jurel*}

Faculty of Dental Sciences, King George Medical University Lucknow, India

The restoration of the unaesthetic anterior teeth has always been a problem, involving large amounts of sound tooth substance, with adverse effects on the pulp and gingiva. The establishment of clear parameters for effective, reliable etching to dental enamel and the development of high quality, microfine composite cements led to introduction of composite veneers for masking discoloration. Unfortunately composites show polymerisation shrinkage staining and poor wear resistance. The acrylic laminate veneers were an attempt to overcome some of these problems, but the long term results were clinically unacceptable.

Porcelain as a material for veneering was first reported by Horn, using commercially available porcelain built up in layers on a platinum foil matrix adapted to the model of the tooth. Further Calamia described a modified technique using high temperature investments. Porcelain is readily etched and the application of the silane couplers to the surface overcame the problem of poor bonding found in acrylic veneer.

A captivating smile showing an even row of natural gleaming white teeth is a major factor in achieving that elusive dominant characteristic known as personality. Dr. Charles pincus in the early 1930 developed thin facing made of air fired porcelain which were temporally held in place with adhesive denture powder and created the Hollywood smile for actors, which was an integral part of image personality and opinion. Since then the art of veneering teeth has progressed over $30 \mathrm{yrs}$ to current generation of concepts and materials

Porcelain laminate veneers: a thin bonded ceramic restoration that restores the facial surfaces and part of the proximal surfaces of the teeth requiring aesthetic restorations (GPT 8).

\section{Types of Veneers}

A) Directly fabricated veneers

B) Indirectly fabricated veneers

\section{Porcelain Laminates}

They can be considered to be very much the state of art in cosmetic dentistry. They are wafer thin shells of porcelain like custom made artificial fingernails.

\section{Advantages \\ - Color \\ - Bond strength}

- Resistance to abrasion

- Periodontal health

- Inherent porcelain strength

- Resistance to fluid absorption

- Esthetics

\section{Disadvantages}

- Time

- Repair

- Technique sensitive

- Fragility

- Cost

\section{Indications}

- Discoloration

- Enamel defects

- Diastema

- Malpositioned teeth

- Malocclusion

- Poor restorations

- $\quad$ Ageing

- Wear patterns

- Agenesis of lateral incisor

\section{Contraindications}

- Available enamel

- Ability to etch enamel

- Oral habits

- Periodontally compromised teeth

All ceramic systems used for porcelain laminate veeners are:

- Conventional (powder- slurry) ceramics

- Castable ceramics

- Machinable ceramics

- Pressable ceramics

- Infiltrated ceramics

\section{Conclusion}

Dentistry has long sought for the ideal restorative material to aesthetically alter unattractive smile. A major breakthrough that facilitated predictable retention of porcelain to tooth structure has added a new dimension to aesthetic dentistry. The strength of porcelain laminates will continue to be assessed although relatively technique sensitive the surface texture, colour, fluorescence and overall aesthetics have been regarded as exceptional.

*Corresponding author: Dr. Sunit Kumar Jurel, BDS, MDS, FAGE, FPFA Assistant Professor (Prosthodontics), Faculty of Dental Sciences, King George Medical University, Lucknow, India, E-mail: dentistmj1110@yahoo.co.in

Received May 04, 2013; Accepted May 06, 2013; Published May 08, 2013

Citation: Jurel SK (2013) An Introduction to Porcelain Laminates. Dentistry 3 : e114. doi:10.4172/2161-1122.1000e114

Copyright: (c) 2013 Jurel SK. This is an open-access article distributed under the terms of the Creative Commons Attribution License, which permits unrestricted use, distribution, and reproduction in any medium, provided the original author and source are credited. 